\title{
WHY A CONTEXTUAL APPROACH TO PROFESSIONAL DEVELOPMENT?
}

\author{
B. L. Leibowitz \\ Faculty of Education \\ University of Johannesburg \\ Johannesburg, South Africa \\ e-mail: brendal@uj.ac.za
}

\section{J. Vorster}

Centre for Higher Education Research, Teaching and Learning

Rhodes University

Grahamstown, South Africa

e-mail: j.vorster@ru.ac.za

\section{Ndebele}

School of Teacher Education and Training

North West University Mafikeng Campus

Mafikeng, South Africa

clever.ndebele@nwu.ac.za

One of the peculiarities of the literature on academic professional development with regard to teaching is its a-political nature. It pays insufficient attention to issues of equity, and to how privilege, geographical location, class and ethnicity influence the way that staff in higher education learn to teach. This is surprising, or paradoxical, given the strong world-wide concern for widening participation and student success in higher education. The approaches towards professional academic development have been dominated by literature from the global North, which does not take into account conditions in resource-constrained environments. We contend that literature from these Southern environments enrich the international body of literature. Thus there is a need for scholarly writing on learning to teach in higher education, which takes a specifically social, contextual and relational approach and which considers these within 
resource-rich as well as resource-constrained environments.

Attention to the social and material influences on professional academic development allows for a nuanced understanding of how to strategise in order to enhance teaching and learning in varied contexts. This should enable academics, who are concerned with their own teaching and with contributing to change in their institutions, to chart appropriate strategies in the current complex and demanding era.

In the literature on professional development there is an increasing call for educational policies to be context sensitive (Mathieson 2012; Trowler 2008; Bamber, Trowler, Saunders and Knight 2009). As an example of this concern with context, Blackmore, Chambers, Huxley and Thackwray (2010) call for 'contextual intelligence'. The word 'context' is often used to denote disciplinary context (cf. Mathieson 2012) or it can denote time, as in the phrase 'in current contexts', or domains such as 'in the political context'. In the literature on situated learning the word 'context' suggests learning occurring through practice (Lave 1996) with a strong emphasis on history and biography (Lave 2012). The word 'context' is taken up in the work of Archer (1995) to imply 'environment in which the ('macro') features of the system are either reproduced or transformed' (Archer 1995, 11). This can refer to any level, from macro to micro.

Higher education institutions are contexts in which features of the sector may be either reproduced or transformed. Context can also refer to levels of the curriculum, for example the contextualised learning needs of lecturers on undergraduate programmes as opposed to those teaching on postgraduate programmes. It can refer to the professional learning of academics at different types of institutions or in different geographical locations. The concern with context can have a more overtly political overtone, for example, there is the need to consider professional academic development in post-colonial contexts or in neo-liberal times. Whatever the perspective adopted by the researcher or academic developer, the fact remains that strategies for the provision of opportunities for academics to learn to teach should take the needs of individual academics into account, as well as the challenges and opportunities generated by the settings in which they work - as the articles in this special issue demonstrate.

Many of the articles in this volume emerge from a large-scale research project funded by the National Research Foundation to explore the influence of context on professional development of academics in their teaching role. Research for this project was conducted across a range of universities across South Africa. These included historically advantaged, researchintensive universities; historically disadvantaged, rural-based universities and universities of technology. This collection includes a number of articles from that project, as well as others 
that are not related to it, but that focus on how context influences professional development.

In the first article of this collection, Naidoo critiques what she calls the evangelical adherence to dominant theories in research and writing on higher education and, in particular, in the field of professional academic development. She argues that to address social justice in higher education it is necessary to theorise in ways that are sensitive to context and that this is not possible if theories are adopted uncritically. Drawing on the work of C. Wright Mills, she suggests that it is possible for higher education researchers in South Africa to engage critically with dominant discourses, and for professional academic development to find creative solutions to local educational challenges that promote social justice and address social inequities and injustices in higher education.

In the next section on professional development programmes, Quinn and Vorster examine aspects of academics' and academic developers' professional learning through formal courses. In their conceptual article, Quinn and Vorster use Luckett's model for an epistemically diverse curriculum, Kitchener's levels of cognition and Maton's concepts of knowledge and knowers to analyse the curriculum for a postgraduate diploma in higher education specifically for academic developers. They argue that a course which prepares academic developers to practise in the complex terrain of contemporary higher education requires participants to engage with specific kinds of knowledge, ways of thinking and ways of being so that they can contribute towards addressing the numerous and vexing teaching and learning challenges in their institutional contexts. Their analysis makes explicit the organising principles of a curriculum for academic developers, so that the curriculum designers are able to use their insights to strengthen the design, pedagogy and assessment of their courses. In addition, making the organising principles explicit to participants enables them to be much more conscious of what, how and why they learn.

Dison critically analyses the role of reflection in a Postgraduate Diploma in Higher Education (PGDip [HE]) at the University of the Witwatersrand. In order to develop critically reflective practice amongst the participants, the course presenters explicitly integrated reflective practice into the pedagogy and assessment of the course. The article reports on the strategies and tools for integrating reflective practice in the first module of the PGDip (HE) and shows how course participants have responded to embedded meta-level questions incorporated into the assessment tasks. The article contributes to a complex understanding of what it means to reflect meaningfully on the outcomes of a professional course of this nature.

In the final article on professional development programmes, Shava looks at the extent to which a professional development programme, the PGDHE at a university in Zimbabwe, has 
enhanced the performance of academics. The findings of this study reveal that participants wanted and needed professional development so that they could improve the quality of their own teaching and that the PGDHE enabled academics to improve their teaching strategies resulting in enhancement of the quality of teaching and learning.

In their articles, Keane and Keane and Castle examine writing development through short courses and workshops. In the first article, Keane and Castle discuss support strategies to enable academics and postgraduate students to write more and better, and to take pleasure in writing. Drawing on published literature and their own experiences of facilitating writing development initiatives, they look critically at writing development strategies used in both their own research-intensive institution in Johannesburg, and strategies used in other institutions, mainly, but not only, in South Africa. They weigh up the benefits and drawbacks of five writing strategies: writing courses and workshops; writing groups; writing mentoring and coaching; $\mathrm{PhD}$ boot camps; and writing retreats. They conclude that some writing strategies can be combined or sequenced to provide the engagement and support academics need to write productively and with pleasure. Keane argues that some of the difficulties experienced by supervisors and students could be addressed through the use of coaching principles and processes. Drawing on Sternberg's (1997) Triarchical Theory, she maintains that integrating aspects of coaching in the design of supervision workshops makes it possible to address consciously the contextual influences on professional academic development. She claims that the coaching aspects of supervisor workshops open up spaces for closer collegiality and that they model empowering, developmental conversations between colleagues.

The next set of articles examines the contextual constraints and/or enablements for academics' engagement in professional development for their teaching role in a range of different institutions. Jawitz and Perez assert that the dominant research discourse in researchintensive universities constrains academics' engagement with professional development opportunities for teaching. Their article reports on a study of narratives that show how a group of academics at the University of Cape Town overcame contextual constraints to assert their agency. The academics justified their engagement in professional development for teaching through alternative pragmatic, social and reflexive approaches. Each of these approaches offers a different basis for justifying the academics' participation in terms of the functions that the professional development opportunities fulfil. In the process, the academics exercise their agency and reduce the power of the dominant research discourse that locates teaching as secondary within the institution.

Ndebele, Muhuru and Nkonki turn the focus to the cultural, structural and agential 
conditions that enable or constrain the professional development of academics in their teaching role at two rurally-based, historically disadvantaged universities. Thematic analysis of the data revealed constraints around promotion policies and the value accorded to research development over teaching development, as well as time constraints resulting from huge workloads and the inability of rural institutions to attract and retain staff. The study recommends that the theoretical frameworks that inform professional development, as well as the practicalities of the modes of delivery of professional development interventions in rural-based universities, need to be reconsidered.

Omingo uses Archer's morphogenetic approach to analyse how lecturers learn to teach in private universities in Kenya. She analyses the emergent structural and cultural powers and the emotions that prompt lecturers, in different contexts, to learn how to teach. Semi-structured interviews were used to collect qualitative data from twenty-five purposively selected lecturers. The analysis indicated that the university's policy statements, the teaching and learning conditions and student composition presented structural and cultural limitations that lecturers had to respond to. Although there were emergent structural and cultural powers that played a role, the lecturers' experience of emotions such as worry, threat, curiosity and disappointment played a greater role in prompting their desire to teach.

The articles by Winberg and Garraway and Cameron and Woods both use Activity Theory to examine aspects of professional development. The focus of the article by Winberg and Garraway is a teaching and learning activity system which is studied for the purpose of understanding and resolving contradictions in the system. They examined the perspectives of university teachers and senior university managers in relation to the activity system. Data was obtained from interviews with university teachers who had expressed an interest in teaching and learning and who had demonstrated considerable ability in university teaching. Interviews were also conducted with senior managers responsible for teaching and learning at the institution. Winberg and Garraway applied the tools provided by Engeström’s Activity Theory to analyse areas of contradiction and make constructive suggestions for using the identified areas of difficulty as sites for growth and development. They also propose ways for university teaching to be supported by university managers in contexts of change and challenge.

Cameron and Woods argue that in institutions of higher education there are clear stages that teachers go through as they gain teaching experience. They analyse and interpret data collected from academic development practitioners during a workshop of the HELTASA (Higher Education Learning and Teaching Association of Southern Africa) Professional Development Special Interest Group, using Activity Theory as their lens. They propose a 
'Ladder of Learning', a hierarchically structured framework to inform appropriate professional development activities focused on teaching and aimed at academics as they progress in their careers from emerging to distinguished practice. Insights gained from the findings and recommendations could be used to strengthen academic professional development practice in higher education institutions in South Africa.

Leibowitz explores the relationship between intrinsic motivation, extrinsic motivation and contextual social and material conditions influencing the desire of academics to learn to teach at three very different South African universities. The article considers these three influences from the perspective of self-determination theory, and shows that the theory is relevant for a discussion on motivation to learn to teach. Leibowitz shows how a careful analysis of these forms of intrinsic and extrinsic motivation in combination with contextual influences has implications for national and institutional policy on professional academic development. Her study suggests that intrinsic forms of motivation might play an important role in encouraging academics to participate in professional development opportunities, but they are rendered less effective by sub-optimal social and material conditions and thus by issues of social injustice and inequality.

The final article in the special issue, by Van Schalkwyk and McMillan, uses duoethnography and the notion of border-crossing to examine how two academic development professionals navigate their insider-outsider positions. The practice of situating academic development practitioners within faculties poses challenges for practitioners from outside the disciplinary space. Literature highlights how discourse and culture create tensions amongst role-players in cross-disciplinary contexts. The article examines the experiences of two practitioners as insider-outsiders in the health sciences. Duoethnography is a collaborative methodology where researchers, in dialogue, critique the meanings they give to social and epistemological constructs. Drawing on the concept of 'border crossing', the study signals how the insider-outsider location of academic development practitioners might be mediated to support quality teaching.

It is hoped that the multiple contexts examined and the theoretical perspectives employed in this collection of articles contribute to understanding the potential effects of various social, material, cultural and agential conditions on academics' engagement with opportunities for professional learning, and that the articles offer insights to academic developers on how context shapes the possibilities for academics’ participation in professional development.

\section{REFERENCES}

Archer, M. 1995. Realist social theory: The morphogenetic approach. Cambridge: Cambridge 
University Press.

Bamber, V., P. Trowler, M. Saunders and P. Knight. 2009. Introduction: Continuities, enhancement and higher education. In Enhancing learning, teaching, assessment and curriculum in higher education, ed. V. Bamber, P. Trowler and M. Saunders, 1-6. Maidenhead: Open University Press and McGraw Hill.

Blackmore, P., J. Chambers, L. Huxley and B. Thackwray. 2010. Tribalism and territoriality in the staff and educational development world. Journal of Further and Higher Education 34(1): 105-117

Lave, J. 1996. Teaching, as learning, in practice. Mind, Culture, and Activity 3(3): 149-164.

Lave, J. 2012. Changing practice. Mind, Culture, and Activity 19(2): 156-171.

Mathieson, S. 2012. Disciplinary cultures of teaching and learning as socially situated practice: rethinking the space between social constructivism and epistemological essentialism from the South African Experience. Higher Education 63: 549-564.

Trowler, P. 2008. Cultures and change in higher education: Theories and practice. Basingstoke: Palgrave MacMillan. 